\title{
O Princípio do Melhor Interesse e a nova Condição Jurídica de Crianças Refugiadas Separadas ou Desacompanhadas: uma abordagem sobre Brasil e Itália
}

Recebido: 11-12-2018

Aprovado: 19-03-2019

Mariana Silva Conte ${ }^{1}$

Paulo Roberto Soares Mendonça ${ }^{2}$

\section{Introdução}

A crise humanitária dos refugiados tem sido alvo de relevante atenção mundial, nos últimos anos, em razão do grande número de pessoas que precisaram abandonar seus países de origem ou residência habitual por motivos de perseguições políticas e religiosas, conflitos internos e ocorrências de violações de direitos humanos para buscarem a concessão do status de refúgio em outros Estados.

Até o final do ano de 2016, 65.600 .000 (sessenta e cinco milhões e seiscentas mil) pessoas foram forçadas a deixar seu local de origem como resultado de perseguições, violência, conflitos e graves infringências de direitos, significando um deslocamento forçado de uma entre cada 113 (cento e treze) pessoas em todo o mundo, sendo 20 (vinte) pessoas por minuto. Desses novos deslocamentos, 22.500 .000 (vinte e dois milhões e quinhentas mil) pessoas foram consideradas refugiadas - de modo que metade delas, $51 \%$ (cinquenta e um por cento), eram crianças - e 2.800 .000 (dois milhões e oitocentas mil) foram consideradas solicitantes de refúgio. (ACNUR, 2017a, p. 2).

Nesse sentido, como se já não bastasse a condição de vulnerabilidade a que são

\footnotetext{
${ }^{1}$ Advogada. Mestranda em Direito pelo Programa de Pós-Graduação em Direito do Centro de Ciências Jurídicas e Políticas da Universidade Federal do Estado do Rio de Janeiro (CCJP/UNIRIO). Atua no Grupo de Pesquisa Relações entre Estado e Direito em um Estado Democrático de Direito do Centro de Ciências Jurídicas e Políticas da Universidade Federal do Estado do Rio de Janeiro (CCJP/UNIRIO) e na linha de pesquisa Infância e Adolescência do Grupo de Pesquisa Direito das Minorias e Fortalecimento de Cidadanias da Faculdade de Direito da Universidade Federal do Ceará (UFC). Brasil. E-mail: marianasconte @ gmail.com

${ }^{2}$ Doutor em Direito pela Universidade do Estado do Rio de Janeiro (UERJ). Professor Adjunto da Pontifícia Universidade Católica do Rio de Janeiro (PUC-RIO). Professor titular da Universidade Federal do Estado do Rio Janeiro, exercendo a docência no curso de Graduação e no Programa de Pós-Graduação em Direito (CCJP/UNIRIO). Diretor da Escola de Ciências Jurídicas da Universidade Federal do Estado do Rio de Janeiro (CCJP/UNIRIO). Brasil. E-mail: pmendonc@uol.com.br
} 
submetidos - ao longo do processo migratório - os indivíduos que buscam refúgio, tal situação caracteriza-se ainda mais expressiva quando se trata da migração de crianças, principalmente aquelas que chegam completamente sozinhas em outros países, de modo que, até o final do ano de 2016, cerca de 75.000 (setenta e cinco mil) menores de idade procuraram asilo individualmente em 70 (setenta) países distintos. (ACNUR, 2017a, p. 47).

Por isso, tem-se que, além de todas as submissões desumanas a que são expostos milhares de seres humanos todos os dias nas fronteiras dos países, as condições de violações de direitos vivenciadas por crianças durante a migração devem merecer especial atenção da comunidade global como um todo, de forma que se garanta o respeito à dignidade humana, principalmente, daquelas que enfrentam o processo estando separadas ou desacompanhadas de pais ou responsáveis.

Ressalta-se, nesta oportunidade, a diferença conceitual existente entre os termos crianças desacompanhadas e separadas. São reconhecidos como crianças desacompanhadas os menores de 18 (dezoito) anos que foram separados de ambos os pais ou responsáveis e não são representados por adulto que, por lei ou costume, possa fazê-lo. Por outro lado, o termo criança separada diz respeito aos menores de idade que foram separados de ambos os pais ou responsáveis legais ou habituais, mas não necessariamente de outros membros adultos da família. (CRC, 2005).

Cabe salientar, ainda, pertinente apontamento terminológico, uma vez que a Convenção sobre Direitos da Criança de 1989 optou por denominar como criança todo ser humano que possui menos de 18 (dezoito) anos de idade. (ONU, 1989). Dessa forma, por serem ambos os países signatários da referida Convenção, o presente trabalho adota tal terminologia para tratar de todos os indivíduos menores de idade ${ }^{3}$, de modo a unificar a nomenclatura utilizada.

Assim, considerando o que pressupõe o princípio do melhor interesse da criança, bem como as condições fáticas de vulnerabilidade vivenciadas por menores de idade que ingressam em outros países separados ou desacompanhados de pais ou responsáveis legais ou por costume, a Itália aprovou a Lei no 47 de 07 de abril de 2017 - conhecida, popularmente, como Lei Zampa - e o Brasil publicou a Resolução Conjunta de 09 de agosto de 2017, almejando a efetivação de direitos desse grupo social específico, através das peculiaridades

\footnotetext{
${ }^{3}$ Importante se faz esclarecer, sobretudo, que, em seu ordenamento jurídico, o Brasil estabeleceu relevante distinção, denominando como criança a pessoa com até 12 (doze) anos de idade incompletos; e como adolescente aquele que possui entre 12 (doze) e 18 (dezoito) anos de idade. Vide artigo $2^{\circ}$ do Estatuto da Criança e do Adolescente.
} 
adiante abordadas.

\section{O Reconhecimento da Infância: a Convenção Internacional de 1989 e a busca do melhor interesse da criança}

A história da consolidação dos direitos da criança e do adolescente demonstra que, apenas recentemente, essa categoria tornou-se assunto de preocupação dos adultos e motivo de especial atenção da comunidade internacional.

Desde os períodos das mais antigas civilizações, os filhos menores de idade não recebiam o status de sujeitos de direitos, mas sim, de propriedades de seu genitor; verdadeiros servos da autoridade paterna (TAVARES, 2001, p. 46).

Numa visão de objetificação da infância, tem-se que, "em Roma (449 a.C), a Lei das XII Tábuas permitia ao pai matar o filho que nascesse disforme (...), sendo que o pai tinha sobre os filhos nascidos de casamento legítimo o direito de vida e de morte e o poder de vendê-los (...).” (AZAMBUJA, 2006, p. 03). Assim, os filhos menores não eram reconhecidos pela sociedade como um indivíduo que a integrava, mas sim, como objetos sobre os quais o pai exercia o direito de proprietário, podendo, até mesmo, decidir sobre a postergação ou não de seu direito à vida.

Considerando, ainda, que, segundo AIRÉS (1981, p. 41), na Idade Média, a criança, precocemente, era inserida à realidade dos adultos, tal período restou marcado pela ausência do sentimento de infância, de modo que não havia lugar no mundo para essa categoria. Essa abordagem acabava por conferir aos sujeitos menores de idade a posição social de "adultos em miniatura".

Nesse aspecto de despersonificação, percebe-se, portanto, que da Antiguidade até a Idade Média o único papel que a criança assumia nas relações jurídicas da sociedade era de ser um bem da família; algo que pertencia ao pai e que se caracterizava por ser, tão somente, uma extensão do núcleo familiar.

Com a Idade Moderna, a sociedade começou a conferir outro olhar às crianças e, consequentemente, os pensamentos dos pais acerca de sua fragilidade e vulnerabilidade foram mudando gradativamente. Assim, a partir do final do século XVI e início do século XVII, começaram a surgir, ainda de forma sutil, vestígios sobre o sentimento de infância, de modo que a criança não era mais um ser anônimo e sem visibilidade própria no meio do mundo adulto.

Apesar de o sentimento de infância ter começado a fazer parte das organizações 
sociais - em razão da instituição das escolas nos séculos XVIII e XIX -, foi a partir do século $\mathrm{XX}$, que os direitos das crianças passaram a ser, efetivamente, objeto de preocupação mundial.

Nessa perspectiva, a edição de alguns documentos internacionais possibilitou uma nova concepção acerca das condições de vulnerabilidade vivenciadas por indivíduos menores de idade, bem como a legitimação de medidas eficazes ao reconhecimento de direitos humanísticos básicos, consolidando, assim, um conjunto normativo internacional sobre direitos da criança: a Declaração de Genebra sobre os Direitos da Criança adotada pela Liga das Nações, em 1924; a Declaração Universal de Direitos Humanos das Nações Unidas, em 1948 e a Declaração Universal dos Direitos da Criança, em 1959, que trazia em seu bojo normativo os preceitos de diversos princípios, dentre os quais, o do superior interesse da criança e o da prioridade.

Estabelecida no ordenamento jurídico internacional, em 1969, a Convenção Americana sobre os Direitos Humanos (Pacto de São José da Costa Rica) - ratificada pelo Brasil através do Decreto $n^{\circ} 678$ de 06 de novembro de 1992 - assim preconiza em seu artigo 19: “Toda criança tem direito às medidas de proteção que a sua condição de menor requer por parte da sua família, da sociedade e do Estado." (OEA, 1969).

A partir da necessidade de implementação de uma normativa internacional mais expressiva, a representação da Polônia na ONU propôs a elaboração de uma Convenção sobre a regulamentação dos direitos das crianças. Assim, a Comissão de Direitos Humanos da ONU organizou um grupo de trabalho aberto com o objetivo de estudar a temática apresentada. Naquela oportunidade, estavam aptos a participar do grupo delegados de qualquer país membro da ONU, além dos representantes obrigatórios dos 43 Estados integrantes da Comissão, organismos internacionais como a UNICEF e grupos de organizações não governamentais criados com essa finalidade. (SARAIVA, 2013, p. 62).

Nesse contexto, após trinta anos da consolidação da Declaração Universal dos Direitos da Criança de 1959 (episódio crucial no ordenamento jurídico internacional no que concerne à afirmação dos direitos dessa categoria), foi aprovada, por unanimidade, na sessão de 20 de novembro de 1989 da Assembleia Geral das Nações Unidas, a Convenção Internacional sobre os Direitos da Criança.

Por apresentar e consolidar os preceitos da Doutrina da Proteção Integral à comunidade global, a referida Convenção passou a ser reconhecida como o documento internacional mais importante no que diz respeito ao reconhecimento dos direitos daqueles 
indivíduos que possuem menos de 18 (dezoito) anos.

Nessa nova concepção normativa, "a proposta da Convenção das Nações Unidas sobre os Direitos da Criança traz consigo outra dimensão ética, pois se reconhece que ao Estado não cabe tutelar pessoas, mas tutelar o direito que é reconhecido às crianças e aos adolescentes, como sujeitos e cidadãos.” (TEJADAS, 2008, p. 41).

Diante disso, a Convenção representa o mínimo de condições básicas que toda organização social deve garantir às crianças e aos adolescentes de sua nação, simbolizando uma ferramenta “(...) para desenvolver um novo esquema de compreensão da relação da criança com o Estado e com as políticas sociais, e um desafio permanente para se conseguir uma verdadeira inserção das crianças e seus interesses nas estruturas e procedimentos dos assuntos públicos.” (BRUÑOL, 2001, p. 92).

A Convenção das Nações Unidas sobre os Direitos da Criança trouxe preceitos de participação, separação e responsabilidade, “(...) procurando equilibrar os direitos da criança com direitos e deveres dos pais ou outros responsáveis, dando-lhe o direito de participar de decisões que afetem o seu presente e também o seu futuro.” (LIBERATI, 2012, p. 34).

Nesse sentido, reconheceu direitos fundamentais aos menores de idade, colocando-os em posição de protagonistas de sua própria realidade e garantindo-lhes a proteção especial, bem como a observância do melhor interesse da criança, conforme preconiza o artigo 3, n. 1, da Convenção: “Todas as ações relativas às crianças, levadas a efeito por instituições públicas ou privadas de bem-estar social, tribunais, autoridades administrativas ou órgãos legislativos, devem considerar, primordialmente, o melhor interesse da criança." (ONU, 1989).

Com previsão em outros artigos, o princípio do melhor interesse da criança preconiza o respeito ao direito das crianças que estejam separadas de um ou de ambos os pais de manter, regularmente, relações pessoais e contato direto com ambos, objetivando um sadio desenvolvimento, salvo situações em que a convivência familiar não seja a melhor opção para a criança; e estabelece, ainda, que os Estados Partes realizem as ações necessárias para garantir que as crianças permaneçam junto a seus pais.

Tendo como referência a ideia de proteção especial, bem como o direito de reconhecimento de suas opiniões, tal princípio busca considerar, sobretudo, “(...) as necessidades da criança em detrimento dos interesses dos pais, devendo realizar-se sempre uma análise do caso concreto.” (PEREIRA, 1999, p. 03).

Dessa maneira, percebe-se que os preceitos trazidos pela Convenção reconhecem a criança como um indivíduo; um ser humano que integra a sociedade e possui poder de 
participação em suas decisões. Apenas a partir desse reconhecimento, é que, de fato, crianças e adolescentes deixaram de ser simples objetos de proteção para, enfim, assumirem o papel de sujeito de direitos.

A referida normativa internacional, então, não dispõe apenas sobre os direitos de crianças e adolescentes de maneira taxativa, mas também, abrange normas de aplicabilidade desses direitos, principalmente no que diz respeito ao seu enfrentamento com direitos de outros indivíduos, garantindo, efetivamente, o melhor interesse da criança, sobretudo, pelo fato de que a categoria abarcada pela Convenção vivencia situações de vulnerabilidade que de longe se assemelham àquelas enfrentadas por outros grupos, merecendo, portanto, uma proteção específica.

\section{O Instituto do Refúgio e sua Aplicação aos Menores de Idade}

A questão dos fluxos migratórios nas diferentes sociedades não se caracteriza como um acontecimento recente na história da humanidade, sendo “(...) seguro presumir que, quando nossos ancestrais se tornaram plenamente humanos, eles já eram migratórios, movimentando-se na caça de grandes animais.” (MCNEILL apud BAUMAN, 2017, p. 82).

Nesse contexto, considerando que, desde os tempos remotos, diversas (ou, talvez, todas) organizações sociais vivenciaram situações de expressivos deslocamentos de seres humanos ao longo da história, não há como negar que o fenômeno da migração contribuiu para o processo de evolução da espécie humana.

Assim, a migração internacional sempre esteve presente nas sociedades, provocando um grande movimento e redirecionamento de pessoas, de forma voluntária ou compulsória, por motivos de expulsões, guerras, revoluções, busca por melhores condições de trabalho, mudanças econômicas, perseguição política, reunião familiar e aperfeiçoamento educacional. (FIRMEZA, 2007, p. 25).

Aliás, em que pese determinadas ramificações de grupos étnicos, a partir de uma visão de "etnonacionalismo" (HABERMAS, 2002, p. 148), considerarem a migração como uma ameaça à soberania nacional dos países de destino (ideia que se consolidou ainda mais depois dos episódios de ataques terroristas nos Estados Unidos e na Europa), certo é que os deslocamentos em grande escala contribuíram para o desenvolvimento social e econômico de diversas nações.

Tratando especificamente do instituto do refúgio, tem-se que suas primeiras definições 
foram formuladas logo após o fim da Primeira Guerra Mundial que, como consequência, estabeleceu inflação, desemprego e guerras civis que culminaram no grande fluxo migratório de indivíduos que “(...) não eram bem-vindos e não podiam ser assimilados em parte alguma. Uma vez fora do país de origem, permaneciam sem lar; quando deixavam o seu Estado, tornavam-se apátridas; quando perdiam os seus direitos humanos, perdiam todos os direitos: eram o refugo da terra." (ARENDT, 1989, p. 300).

Citando lições de Hathaway (1991) e Fischel de Andrade (1996), Araújo e Barrichello (2015, p. 116) lecionam que o reconhecimento da condição de refúgio pode ser dividido em um momento de caráter objetivo (1921 - 1939), em que era atribuído o status de refugiado através de uma definição jurídica concedida a determinado grupo étnico ou nacional ao qual o indivíduo pertencia e que, diante das condições vivenciadas, necessitasse de proteção; ${ }^{4}$ e em uma perspectiva individualista (1938 - 1951), que restou caracterizada pela análise subjetiva do caso concreto de modo que era conferida a condição de refúgio às pessoas que tivessem sido afetadas por evento político ou social, independentemente de enquadramento conceitual em determinado grupo específico.

Ainda abordando um cenário de pós Primeira Guerra Mundial, fora criada, em 1919, a Liga das Nações que, por sua vez, tinha como objetivo principal assegurar a paz entre os países. Tal organização possibilitou, em 1933, o surgimento da Convenção Relativa ao Estatuto Internacional dos Refugiados que consolidou a política de não restrição na qualificação de refugiados, bem como estabeleceu, em seu artigo $3^{\circ}$, o princípio do nonrefoulement, determinando que os Estados não deveriam obrigar uma pessoa a retornar ao seu território, caso estivesse exposta a algum tipo de perseguição, ou seja, não poderiam repelir, em nenhuma hipótese, indivíduos que precisassem de proteção internacional. (LIGA DAS NAÇÕES, 1933).

Todavia, considerando que a Liga das Nações não conseguiu impedir o acontecimento da Segunda Guerra Mundial, bem como que as consequências humanitárias desse conflito foram exponencialmente maiores que as do primeiro, fez-se necessária a reformulação da Liga e a consequente criação da Organização das Nações Unidas, em 1945, e a aprovação da Declaração Universal dos Direitos Humanos, em 1948.

\footnotetext{
${ }^{4}$ Importante se faz esclarecer, nesta oportunidade, que Araújo e Barrichello (2015, p. 117) pontuam que a proposta apresentada por Hathaway divide a perspectiva de caráter objetivo em duas concepções: jurídica (19201935) e social (1935-1939). Na primeira, os grupos determinados recebem um reconhecimento jurídico; já na segunda, assistência internacional em virtude de ocorrência de eventos políticos e sociais, principalmente aqueles relacionados ao Nazismo.
} 
(...) os novos refugiados não eram perseguidos por algo que tivessem feito ou pensado, e sim, em virtude daquilo que imutavelmente eram - nascidos na raça errada (como no caso dos judeus na Alemanha), ou na classe errada (como no caso dos aristocratas na Rússia), ou convocados pelo governo errado (como no caso dos soldados do Exército Republicano espanhol). (ARENDT, 1989, p. 328).

Consolidando a questão do refúgio, a referida Declaração reconheceu, em seu artigo 13, o direito de toda pessoa abandonar o país em que se encontra, incluindo o seu próprio e, além disso, estabeleceu, em seu artigo 14, o direito de toda pessoa sujeita à perseguição buscar asilo em outros países. (ONU, 1948).

Diante de toda preocupação com a situação do refúgio e seguindo a ideia de efetivação dos direitos humanos, fora criado, em 14 de dezembro de 1950, o Alto Comissariado das Nações Unidas para Refugiados (ACNUR) e adotada, em 28 de julho de 1951, a Convenção das Nações Unidas relativa ao Estatuto dos Refugiados que, com o objetivo de proteger as pessoas vítimas de perseguição, intolerância e violência, apresentou critérios mais amplos de concessão do status de refugiado e ratificou a incidência do princípio do non-refoulement no tratamento desses indivíduos.

Segundo o artigo $1^{\circ}$ do referido Estatuto, considera-se refugiada qualquer pessoa que, em decorrência de acontecimentos anteriores a $1^{\circ}$ de janeiro de 1951 e temendo possível perseguição por motivos de religião, raça, grupo social, nacionalidade ou opiniões políticas, esteja fora do seu país de origem e não possa ou, em razão desse temor, não deseje usufruir da proteção desse Estado, ou que, caso não possua nacionalidade e esteja fora do país no qual mantinha sua residência habitual, não possa ou, em virtude do referido temor, não deseje retornar a ele. (ACNUR, 1951).

Apesar do grande avanço de regulamentação internacional apresentado, observa-se, através da leitura do seu artigo $1^{\circ}$, que a Convenção das Nações Unidas relativa ao Estatuto dos Refugiados versa sobre os acontecimentos ocorridos antes de $1^{\circ}$ de janeiro de 1951; situação esta que implicou a submissão de um Protocolo à Assembleia Geral das Nações Unidas, em 1966, com o objetivo de abarcar os novos fluxos de refugiados na normativa protetiva estabelecida pela Convenção.

Como consequência da ratificação do Protocolo, em 1967, os países passaram a aplicar os preceitos do Estatuto de 1951 a todas as pessoas que se enquadravam na definição de refugiado, independente de observação geográfica ou temporal, de modo que, até os dias atuais, a complementação normativa de ambos é considerada o principal mecanismo internacional de proteção aos refugiados. 
Além da regulamentação prevista nesses documentos, importante se faz ressaltar que, no âmbito da América Latina, a situação dos refugiados sofreu um acréscimo conceitual através da Declaração de Cartagena de 1984, bem como teve reconhecida a necessidade de implementação de medidas mais eficazes a partir da Declaração e do Plano de Ação do México para Fortalecer a Proteção Internacional dos Refugiados de 2004 e da Declaração de Brasília sobre Proteção aos Refugiados e Apátridas no Continente Americano de 2010.

(...) a definição ou o conceito de refugiado recomendável para sua utilização na região é o que, além de conter os elementos da Convenção de 1951 e do Protocolo de 1967, considere também como refugiados as pessoas que tenham fugido dos seus países porque a sua vida, segurança ou liberdade tenham sido ameaçadas pela violência generalizada, a agressão estrangeira, os conflitos internos, a violação maciça dos direitos humanos ou outras circunstâncias que tenham perturbado gravemente a ordem pública. (ACNUR, 1984).

Nessa perspectiva, Boed (1994, p. 01) ressalta que o direito de refúgio pode ser identificado através de três direitos distintos: o direito de o Estado garantir o refúgio; o direito de uma pessoa solicitar refúgio e, por fim, o direito de um indivíduo obter refúgio. Dessa forma, sendo garantidos a qualquer pessoa, é certo que o status de refugiado possibilita, inclusive, aplicação extensiva aos indivíduos menores de idade.

Ainda que diante da ausência de normatização específica, a Constituição da Organização Internacional dos Refugiados (1946) já previa que o conceito de refugiado era aplicado a "crianças não acompanhadas que são órfãs de guerra ou cujos pais desapareceram e que estão fora de seus países de origem." (IRO, 1946).

Considerando a normativa internacional que versa, atualmente, sobre a definição de refugiado (Convenção das Nações Unidas relativa ao Estatuto dos Refugiados de 1951 e Protocolo de Nova Iorque de 1967), verifica-se que, apesar de sua expressiva abrangência conceitual, não há dispositivo peculiar que regulamente as condições vivenciadas por indivíduos menores de idade que sofrem algum tipo de perseguição de cunho religioso, social, político ou racial.

Entretanto, é certo que tal omissão normativa específica fora suprimida com o advento da já mencionada Convenção da Organização das Nações Unidas sobre Direitos da Criança (1989) que regulamenta, em seu artigo 22, a possibilidade de concessão de status de refugiado aos menores de idade.

O referido artigo pressupõe que os Estados Partes deverão adotar as providências cabíveis para garantir que as crianças solicitantes de refúgio ou já consideradas refugiadas recebam, independentemente de estarem sozinhas ou acompanhadas, a proteção e assistência 
humanitária adequada a possibilitar a consolidação e efetivação dos direitos previstos na respectiva Convenção, bem como em demais diplomas internacionais de direitos humanos. Além disso, prevê que os Estados Partes deverão cooperar com as Nações Unidas e as demais organizações intergovernamentais e não governamentais que auxiliem a ONU, de modo a ajudar e proteger a criança refugiada e de localizar seus pais ou outros membros de sua família, a fim de possibilitar a reunião familiar, sendo certo que, na impossibilidade de localização, deverá ser concedida à criança a mesma proteção conferida a qualquer outra que esteja privada do convívio familiar. (ONU, 1989).

Reconhecidos, portanto, como sujeitos plenos de direitos pela Convenção de 1989, não há dúvidas de que o status de refugiado deve ter aplicação extensiva aos indivíduos menores de idade que, independentemente de estarem sozinhos ou acompanhados, não possam ou temam retornar ao país de origem ou de residência habitual, em razão de possível perseguição por motivo racial, político, religioso, social ou de nacionalidade.

\section{Crianças Refugiadas Desacompanhadas na Itália: A nova condição jurídica implementada pela Lei Zampa}

A crise migratória na Europa representa a drástica situação humanitária vivenciada por milhares de pessoas que, em virtude de perseguições, fome e guerras, tentam buscar, nos países europeus, refúgio, asilo e proteção, mas acabam sendo vítimas das condições de vulnerabilidade proporcionadas pela ação de grupos que controlam os deslocamentos desses indivíduos durante a travessia do mar Mediterrâneo.

Apesar de o grande fluxo migratório ter atingido números críticos no ano de 2015, a União Europeia registrou uma queda no número de pedidos de proteção internacional, de maneira que representaram 1.322.825 (um milhão, trezentos e vinte e dois mil, oitocentos e vinte e cinco) naquele ano, 1.259 .955 (um milhão, duzentos e cinquenta e nove mil, novecentos e cinquenta e cinco) em 2016 e 327.725 (trezentos e vinte e sete mil, setecentos e vinte e cinco) até o mês de junho de 2017 (43,3\% menor que o mesmo período do ano anterior). (SPRAR, 2017a, p. 7-8).

Todavia, apesar da redução no número de pedidos de proteção internacional, certo é que a crise migratória ainda se faz motivo de fundada preocupação dos países europeus que, em virtude de uma passagem mais acessível, continuam recebendo muitas pessoas que precisaram deixar seus locais de origem, principalmente, nas principais portas de ingresso da Europa: Itália, Alemanha e Bulgária. (SPRAR, 2017a, p. 7). 
Como se já não bastasse a preocupação recorrente com a situação vivenciada pelos imigrantes, a atenção maior tem se fundado nas condições a que são submetidas as crianças que são obrigadas a deixar seus países, de modo que, até o final de 2016, elas representavam $51 \%$ (cinquenta e um por cento) do total de refugiados no mundo. (ACNUR, 2017a, p. 2).

Nessa perspectiva, verifica-se que as condições de vulnerabilidade são ainda mais alarmantes quando se trata de crianças que enfrentam o processo migratório separadas ou desacompanhadas de pais ou responsáveis. Segundo dados do Alto Comissariado das Nações Unidas para Refugiados (2017a, p. 47), até o final de 2016, cerca de 75.000 (setenta e cinco mil) crianças procuraram asilo individualmente em 70 (setenta) países.

Crianças desacompanhadas ou separadas representavam um contingente estimado entre $2 \%$ (dois por cento) a $5 \%$ (cinco por cento) da população de menores de idade que buscavam refúgio (WCRCW, 2002, p. 4). Todavia, das 16.524 (dezesseis mil, quinhentas e vinte e quatro) crianças que chegaram à Espanha, Grécia, Itália e Bulgária, até a primeira metade do ano de 2017, 11.918 (onze mil, novecentas e dezoito) delas estavam em situação de desacompanhamento ou separação, representando, assim, $72 \%$ (setenta e dois por cento) do total. (ACNUR, 2017b, p. 1).

No que se refere, especificamente, à Itália tem-se que cerca de 25.900 (vinte e cinco mil e novecentas) crianças separadas ou desacompanhadas chegaram ao país em 2016. (ACNUR, 2017a, p. 47). Com relação ao primeiro semestre de 2017, 15\% (quinze por cento) do total de refugiados que chegaram ao território italiano eram crianças, perfazendo um total de 12.239 (doze mil, duzentas e trinta e nove). Dessas, 11.406 (onze mil quatrocentas e seis) delas estavam separadas ou desacompanhadas, representando $93 \%$ do número total de crianças que adentram no país. Quase metade deste contingente é oriundo da Guiné, Costa do Marfim, Bangladesh e Gambia (ACNUR, 2017b, p. 1).

Diante do grande número de crianças desacompanhadas e separadas que adentram o território italiano, bem como pelo fato de que a Itália apresenta um índice de rejeição de, aproximadamente, $50 \%$ (cinquenta por cento) dos pedidos de proteção internacional (SPRAR, 2017b, p. 199), fora aprovada, no país, a Lei n. 47 de 07 de abril de 2017 que versa sobre medidas de proteção aplicadas a crianças estrangeiras não acompanhadas. ${ }^{5}$

(...) criança estrangeira não acompanhada presente no território do Estado significa um menor de

\footnotetext{
${ }^{5}$ Não obstante a legislação italiana adote o termo "crianças desacompanhadas", verifica-se, a partir da leitura da lei e da aplicabilidade do texto normativo, que as garantias também são extensivas aos menores de idade que são considerados separados.
} 
idade que não seja cidadão italiano ou da União Europeia e que esteja, por qualquer motivo, no território do Estado ou, de outra forma, sujeito à jurisdição italiana, sem assistência e representação de pais ou outros adultos legalmente responsáveis por ele, de acordo com as leis vigentes no sistema jurídico italiano. (ITÁLIA, 2017).

Buscando a efetivação de direitos básicos desse público específico, a referida lei estabeleceu diversas modificações na normativa temática vigente, implementando um sistema nacional de proteção e acolhida que almeja, sobretudo, reforçar os instrumentos protetivos já existentes e garantir a homogeneidade na aplicação das disposições relativas a esse grupo social.

Embora popularmente conhecida como "Lei Zampa" - em virtude da contribuição de sua primeira signatária: a parlamentar Sandra Zampa -, a organização não governamental Save the Children fora responsável, inicialmente, por sua formulação e sua posterior apresentação ao Parlamento Italiano, em julho de 2013.

A referida legislação caracteriza-se como um documento inovador e pioneiro na União Europeia, de modo que, através de sua entrada em vigor, concedeu à Itália o status de primeiro país europeu a adotar um sistema integrado de proteção que reconhece as condições de vulnerabilidade vivenciadas por crianças estrangeiras desacompanhadas de pais e responsáveis que ingressam no país, colocando tais indivíduos numa escala superior de atenção e prioridade.

Reconhecendo que os menores de idade estrangeiros que chegam sozinhos ao país estão submetidos a uma maior vulnerabilidade, a lei considera que tais crianças sejam titulares dos mesmos direitos conferidos às italianas ou àquelas que possuam cidadania na União Europeia (ITÁLIA, 2017), a fim de que possam usufruir de direitos substanciais como saúde, educação e assistência legal.

Com o objetivo de garantir a efetivação desses direitos, o texto normativo prevê, em seu artigo 11, a figura do tutor voluntário que, selecionado dentre os cidadãos italianos e devidamente treinado para o exercício da função, ficaria responsável por cuidar dos interesses de determinada criança estrangeira desacompanhada ou de grupo de irmãos nessa condição. (ITÁLIA, 2017).

Assim, numa perspectiva de parentalidade social, o tutor voluntário executa tarefas de representação legal da criança; adota as medidas cabíveis para o reconhecimento de seus direitos, sem quaisquer distinções; promove seu bem-estar social, físico e psicológico; administra eventual patrimônio do qual a criança seja titular e monitora suas condições de 
educação, integração, recepção, segurança e proteção. (SALESIANI PER IL SOCIALE, 2017, p. 5).

Além dessas inovações, a Lei n. 47/2017 estabelece, dentre outras previsões, a proibição expressa de rejeição de crianças estrangeiras desacompanhadas na fronteira; a criação de um banco de dados nacional em que constem informações, a partir de um histórico social e familiar, sobre os menores de idade não acompanhados que chegam ao país; um sistema procedimental que garanta a identificação, localização e a eventual reaproximação dos seus familiares; bem como, a possibilidade de extensão (até os vinte e um anos de idade) do acesso aos serviços sociais ao jovem que, após ter completado a maioridade, ainda tenha dificuldade de inserção social. (ITÁLIA, 2017).

Nesse contexto, fundamentada no princípio do melhor interesse da criança - inserido no ordenamento internacional pela Convenção de 1989 -, a promulgação da "Lei Zampa" pode ser considerada como uma medida oportuna e colaborativa para efetivação de direitos de crianças separadas ou desacompanhadas que atravessam o Mediterrâneo na incansável busca por sobrevivência.

Portanto, em que pese o pouco tempo de sua entrada em vigor e a consequente ausência de dados sólidos sobre sua eficácia não permitirem averiguar os efeitos práticos da referida lei, verifica-se que a previsão de direitos específicos dessa categoria já pode ser considerada um grande avanço legislativo para a comunidade internacional, eis que reconhece a condição de vulnerabilidade extrema a que estão sujeitas as crianças estrangeiras não acompanhadas que adentram o país.

\section{A Realidade Brasileira: Da ausência de regulamentação específica à Resolução Conjunta de 09 de agosto de 2017}

Além da Convenção das Nações Unidas sobre o Estatuto dos Refugiados de 1951 e o Protocolo de 1967, a situação do refúgio no contexto do ordenamento jurídico brasileiro é positivada pela Lei n ${ }^{\circ} 9.474$ de 22 de julho de 1997 que, por sua vez, criou o Comitê Nacional para Refugiados (CONARE) e estabeleceu uma definição mais abrangente para a concessão do refúgio, considerando refugiado todo indivíduo que:

\footnotetext{
Art. $1^{\circ}(\ldots)$

I - devido a fundados temores de perseguição por motivos de raça, religião, nacionalidade, grupo social ou opiniões políticas encontre-se fora de seu país de nacionalidade e não possa ou não queira acolher-se à proteção de tal país;

II - não tendo nacionalidade e estando fora do país onde antes teve sua residência habitual, não
} 
possa ou não queira regressar a ele, em função das circunstâncias descritas no inciso anterior; III - devido a grave e generalizada violação de direitos humanos, é obrigado a deixar seu país de nacionalidade para buscar refúgio em outro país. (BRASIL, 1997).

Ressalta-se, ainda, que, no ano passado, fora promulgada a Lei $n^{\circ} .13 .445$ de 24 de maio de 2017 que, apesar de tratar de forma mais genérica sobre a questão da imigração, também influencia nas condições vivenciadas pelos refugiados no Brasil, uma vez que, ao legislar a situação geral dos estrangeiros no país, deve ser aplicada de forma subsidiária aos casos concretos não abordados pelos demais documentos normativos.

A referida lei estabelece parâmetros de simplificação e ampliação da regularização migratória, além do reconhecimento da condição de apátrida, bem como da naturalização facilitada, de acordo com os critérios legalmente estabelecidos. (BRASIL, 2017).

Além disso, recentemente, entrou em vigor a Lei no 13.684 de 21 de junho de 2018 que versa sobre medidas de assistência emergencial para acolhimento a pessoas em situação de vulnerabilidade decorrente de fluxo migratório provocado por crise humanitária. E, nesse contexto, apresenta no inciso VI do seu artigo $5^{\circ}$ que tais medidas visam à ampliação das políticas de proteção de diversos grupos sociais vulneráveis, inclusive crianças e adolescentes. (BRASIL, 2018).

Apesar de serem caracterizados como avanços legislativos em virtude de seus princípios humanitários, os textos normativos citados não preveem, assim como no âmbito do ordenamento internacional, regras específicas que regulamentem as condições a que são submetidas as crianças em situação de refúgio no território brasileiro, ocasionando uma brecha legislativa quanto ao assunto.

Segundo dados do Comitê Nacional para Refugiados (2017), no Brasil, até o final de 2016, 9.552 (nove mil, quinhentas e cinquentas e duas) pessoas de 82 (oitenta e duas) nacionalidades diferentes tiveram sua condição de refugiada devidamente reconhecida, caracterizando, naquele ano, um aumento de $12 \%$ (doze por cento) no número total de refugiados reconhecidos no país.

No que se refere às solicitações de refúgio, foram 28.385 (vinte e oito mil, trezentas e oitenta e cinco) em 2014; 28.670 (vinte e oito mil, seiscentas e setenta) em 2015 e 10.308 (dez mil, trezentas e oito) em 2016, constatando-se uma diminuição de 64\% (sessenta e quatro por centro) neste último ano com relação ao ano anterior. Ainda nesse sentido, observa-se que, em 2016, 11\% (onze por cento) das pessoas que requereram a concessão do status de refúgio tinham menos de 18 (dezoito) anos e que 9\% (nove por cento) dos pedidos foram concedidos 
a essa categoria. (CONARE, 2017).

Atualmente, segundo o último documento "Refúgio em números" divulgado recentemente, até o final do ano passado, o Brasil reconheceu a condição de refugiado a 10.145 (dez mil, cento e quarenta e cinco) pessoas, sendo que 5.134 (cinco mil, cento e trinta e quatro) delas residem em território nacional. E, apenas no ano de 2017, reconheceu 587 (quinhentos e oitenta e sete) refugiados, sendo $20 \%$ (vinte por cento) deles menores de 18 (dezoito) anos. (CONARE, 2018).

No que diz respeito às solicitações de refúgio, o país recebeu, em sete anos, segundo os referidos dados, 126.102 (cento e vinte e seis mil e cento e duas) solicitações de reconhecimento de refúgio, sendo certo que 86.007 (oitenta e seis mil e sete) ainda estão em trâmite e 33.866 (trinta e três mil, oitocentas e sessenta e seis) delas foram requeridas apenas no ano de 2017. (CONARE, 2018).

De acordo com os dados da pesquisa elaborada pela equipe técnica do Instituto de Pesquisa Econômica Aplicada (IPEA), no ano de 2013, das 140 (cento e quarenta) crianças que solicitaram o reconhecimento da condição de refugiado no Brasil, 20 (vinte) delas chegaram ao país desacompanhadas ou separadas. Além disso, dos menores de idade titulares da $\operatorname{amostra}^{6}$ da pesquisa, aproximadamente $38 \%$ (trinta e oito por cento) deles vieram desacompanhados e 5,0\% (cinco por cento) separados, cabendo ressaltar que o mais novo dentre eles tinha, tão somente, 8 (oito) anos de idade. (LIMA et.al., 2017, p. 72 e 114).

Atualmente, segundo informações fornecidas pelo CONARE, através de solicitação formal realizada pelo Sistema Eletrônico do Serviço de Informação ao Cidadão (e - SIC) ao Ministério da Justiça ${ }^{7}$, de janeiro a junho de 2018, houve 161 (cento e sessenta e um) pedidos de reconhecimento de refúgio na faixa etária entre 0 a 12 anos e 67 (sessenta e sete) solicitações da faixa etária entre 13 a 17 anos de idade. Naquela oportunidade, a coordenação do Comitê informou, ainda, não possuir dados sistematizados anteriores a 2018 sobre crianças e adolescentes solicitantes de refúgio e, tampouco, sobre aqueles que estariam, eventualmente, separados ou desacompanhados de pais ou responsáveis.

Tratando, especificamente, da situação jurídica de crianças e adolescentes no Brasil, contrapondo-se aos preceitos estabelecidos na Doutrina da Situação Irregular - que

\footnotetext{
${ }^{6}$ Para a realização da pesquisa elaborada pela equipe técnica do IPEA, fora considerada uma amostra composta de 4.150 (quatro mil cento e cinquenta) processos deferidos, ressaltando-se que o referido número não representa a quantidade de refúgios reconhecidos, eis que cada processo pode conter mais de uma solicitação (titular e seus acompanhantes).

${ }^{7}$ A solicitação ao Sistema de Informação fora formalizada através do protocolo 08850004137201871 realizado em 22 de agosto de 2018 por meio de senha de uso pessoal e intransferível no site correspondente.
} 
considerava os menores de idade como objetos de proteção e não como sujeitos de direitos - a Constituição da República Federativa do Brasil de 1988 e o Estatuto da Criança e do Adolescente de 1990 disseminaram, no país, a Doutrina da Proteção Integral que, por sua vez, reconhece direitos e garantias fundamentais inerentes àqueles indivíduos menores de 18 (dezoito) anos.

Tem-se, portanto, que "pela primeira vez na história das Constituições brasileiras, o problema da criança é tratado como uma questão pública e abordado de forma profunda, atingindo, radicalmente, o sistema jurídico.” (LIBERATI, 2006, p. 27).

A partir da instauração desse novo ordenamento jurídico, todas as crianças e adolescentes passaram a ser reconhecidos como sujeitos plenos de direito, sendo caracterizados, sobretudo, por sua peculiar condição de pessoa em desenvolvimento. Assim como os adultos, crianças e adolescentes receberam o status de titulares de direitos fundamentais e se tornaram protagonistas de sua própria realidade, podendo interagir com o respectivo Sistema de Justiça.

Nessa nova ordem jurídica, as opiniões de crianças e adolescentes são devidamente consideradas e o juiz responsável pela Vara da Infância e da Juventude tem seus "poderes" limitados pelo sistema de garantias de direitos (BELOFF, 2004, p. 18-21); situação esta que coíbe, portanto, a intervenção estatal coercitiva ilimitada e oferece ao indivíduo menor de idade condições de participação nos assuntos que dizem respeito à consolidação e ao reconhecimento dos seus direitos.

Diante dessa nova realidade, observa-se, acima de tudo, a expressiva incidência do princípio da prioridade absoluta previsto no artigo 227 da Constituição da República Federativa do Brasil e no artigo $4^{\circ}$ do Estatuto da Criança e do Adolescente. ${ }^{8}$ Tal princípio “(...) é o norte para a efetivação dos demais direitos e garantias fundamentais, retratando um 'priorizar' à infância e juventude, desde o recém-nascido ao adolescente". (FONSECA, 2012, p.18).

Tal garantia constitucional pressupõe o estabelecimento de um sistema que priorize a efetivação de direitos de crianças e adolescentes, de modo que seja conferido a essa categoria um atendimento prioritário nos serviços públicos, bem como preferência na formulação e na execução das políticas públicas.

Dessa forma, o princípio da prioridade absoluta fundamenta o sistema de garantias de

\footnotetext{
${ }^{8}$ Sobre o assunto, vide redação dos respectivos artigos.
} 
direitos que estabelece parâmetros para o funcionamento de uma política pública que priorize o atendimento a crianças e adolescentes, sem que sejam estabelecidas quaisquer distinções. (SARAIVA, 2013, p.92).

Portanto, a prioridade absoluta deve ser concedida a qualquer criança ou adolescente, independentemente de suas condições sociais, físicas e étnicas, na medida em que seja conferido a essa categoria um atendimento prioritário nos serviços públicos, bem como preferência na formulação e na execução das políticas públicas.

Nesse sentido, em atenção ao que pressupõem os princípios disciplinados na Convenção sobre Direitos da Criança de 1989, é certo que, sendo aplicado a todas as crianças e adolescentes, o princípio constitucional da prioridade absoluta deve abarcar, inclusive, a efetivação dos direitos e garantias fundamentais concernentes às crianças estrangeiras que chegam ao país buscando refúgio, principalmente aquelas que adentram no território brasileiro separadas ou desacompanhadas de pais ou responsáveis.

Considerando, portanto, os preceitos da Doutrina da Proteção Integral, as condições de extrema vulnerabilidade vivenciadas por menores de idade que ingressam sozinhos no país, bem como a ausência de normatização específica sobre a temática, fora publicada a Resolução Conjunta de 09 de agosto de 2017, assinada por representantes do Conselho Nacional dos Direitos da Criança e do Adolescente (CONANDA); do Comitê Nacional para os Refugiados (CONARE); do Conselho Nacional de Imigração (CNIg) e da Defensoria Pública da União (DPU).

Tal resolução é o primeiro ato normativo brasileiro a abordar, de maneira peculiar, a questão de crianças estrangeiras que chegam desacompanhadas ou separadas no país, estabelecendo, sobretudo, procedimentos de identificação preliminar, atenção e proteção desse público específico.

O referido documento dispõe sobre a aplicação integral da política de atendimento à criança e ao adolescente, em igualdade de condições, a todos os menores de idade estrangeiros que ingressem sozinhos no país; a garantia de agilidade e prioridade na tramitação dos respectivos processos administrativos; a não aplicação de medida de retirada compulsória para local em que seus direitos estejam ameaçados de violação; o respeito ao princípio da não devolução (non-refoulement); os procedimentos que devem ser adotados pelas autoridades fronteiriças e, posteriormente, pela Defensoria Pública da União na identificação e atendimento dessas crianças e adolescentes. (CONANDA; CONARE; CNIg; DPU, 2017). 
Assim, ainda que represente um avanço no que se refere à regulamentação da situação de crianças e adolescentes separadas ou desacompanhadas que chegam ao país, verifica-se, a partir da leitura da resolução e de uma análise comparativa com a legislação italiana, que a normatização brasileira não é abrangente de modo a estabelecer critérios práticos de efetivação dos direitos desses menores de idade que, conforme já ressaltado, vivenciam situações de extrema vulnerabilidade.

Ao determinar os procedimentos de identificação e, posteriormente, de atendimento pela Defensoria Pública da União - colocando-a como responsável pelos pedidos de regularização migratória, solicitação de documentos e demais atos de proteção - a resolução acaba por se limitar ao anseio de garantir a atenção na fase preliminar da situação vivenciada por crianças e adolescentes separadas ou desacompanhadas sem prever meios práticos para uma efetivação futura de seus direitos fundamentais como, por exemplo, através da figura do tutor voluntário previsto na legislação italiana. ${ }^{9}$

Tal deficiência ocorre, inclusive, pelo fato de o texto estar previsto em uma resolução que, apesar de seu inegável caráter regulamentar (CARVALHO FILHO, 2015, p. 58), não pode ser considerada uma lei e, por isso, não possui o mesmo status impositivo e extensivo necessários ao caso, caracterizando a situação da criança como algo precário e frágil tanto no âmbito normativo quanto social.

Diante disso, embora o reconhecimento da necessidade de regulamentação da temática seja considerado um grande passo para a efetivação dos direitos de crianças estrangeiras desacompanhadas ou separadas que ingressam no país, seria interessante que o Brasil, seguindo o exemplo italiano, promulgasse uma lei que versasse sobre o assunto, a fim de estabelecer medidas protetivas mais abrangentes para esse público.

Ademais, a própria ausência de informações consolidadas sobre a existência de crianças separadas ou desacompanhadas em território nacional, bem como a precariedade normativa que norteia os casos dessa categoria já demonstram pouca preocupação com a questão apresentada. Isso porque, mesmo que existam leis gerais que visem proteger as pessoas que buscam refúgio no país, a condição de vulnerabilidade vivenciada pela criança necessita de uma atenção especial por parte do Estado.

\footnotetext{
${ }^{9}$ A eventual propositura de ação judicial acabará por ensejar na nomeação de um tutor para cuidar dos interesses de crianças estrangeiras desacompanhadas ou separadas. Todavia, a previsão legislativa da figura do tutor voluntário - como acontece no caso italiano - resultaria em um procedimento mais célere e eficaz para a resolução do problema de ausência de representação legal dessa criança que, em razão de sua condição de extrema vulnerabilidade, necessita de urgente atenção.
} 


\section{Conclusão}

Tendo como base princípios de solidariedade e cooperação entre as diferentes civilizações, compreende-se o instituto do refúgio, além de sua concepção jurídico-positiva, como um verdadeiro pressuposto humanitário e altruístico entre os povos e que ocupa, atualmente, o centro das discussões de política externa e relações internacionais, principalmente, no continente europeu.

Considerando, portanto, o aumento das solicitações de concessão de refúgio nos últimos anos, tal questão vem se tornando de relevante discussão no cenário mundial, levando diversos países a reformularem eventuais conceitos e parâmetros de atuação cabíveis para lidar com a problematização da temática.

Nesse aspecto, tem-se que as condições desumanas vivenciadas por crianças durante o processo migratório ensejaram uma maior preocupação dos Estados com essa categoria específica - merecendo, inclusive, ampla cobertura midiática -, visto que se trata de grupo social extremamente vulnerável não apenas pela situação que ensejou a respectiva migração, mas, igualmente, pela natural vulnerabilidade da criança, devidamente reconhecida pela Convenção de 1989.

Diante disso, fundada no princípio do melhor interesse da criança, a Lei Zampa estabelece a precípua vulnerabilidade de pessoas menores de idade, merecendo tratamento igualitário, independentemente de sua origem e status social. As questões religiosas, raciais, políticas, étnicas e de nacionalidade deixam de ser fundamentais para o reconhecimento deste novo tipo de refugiado, de modo que até mesmo aquela criança que ingressou no país desacompanhada ou separada dos pais ou responsáveis legais deverá ser acolhida de forma idêntica aos demais.

Nessa mesma perspectiva, ao aprovar a Resolução Conjunta de 09 de agosto de 2017, o Brasil buscou estabelecer métodos de efetivação de direitos fundamentais inerentes às crianças que chegam separadas ou desacompanhadas ao país, reconhecendo a aplicabilidade igualitária do sistema de garantia de direitos como um todo.

Todavia, em que pese já seja um avanço no que se refere à regulamentação da situação dessas crianças que ingressam sozinhas no território brasileiro, cabe salientar que seria interessante que o Brasil, seguindo o exemplo italiano, promulgasse uma lei que versasse sobre o assunto, uma vez que a resolução é ato normativo frágil que não tem status de lei e pode ser derrubada com facilidade, colocando em risco as garantias conferidas a esse público 
e o respeito a sua condição de pessoa em desenvolvimento.

De qualquer forma, ainda que haja a necessidade de uma legislação específica no Brasil, é certo que ambos os documentos normativos ditam um novo rumo de fluxos migratórios, levando a discussão a um patamar centrado na questão humanitária, bem como no reconhecimento da criança como sujeito pleno de direitos e não como mera extensão do núcleo familiar ou simples objeto de proteção do Estado.

\section{Referências}

AIRÉS, Philippe. História Social da Criança e da Família. Tradução de Dora Flasksman. Rio de Janeiro: LTC, 1981.

ALTO COMISSARIADO DAS NAÇÕES UNIDAS PARA REFUGIADOS (ACNUR). Convenção relativa ao estatuto dos refugiados (1951). Disponível em: < http://www.acnur.org/fileadmin/scripts/doc.php?file=fileadmin/Documentos/portugues/BDL/ Convencao_relativa_ao_Estatuto_dos_Refugiados>. Acesso em: 22 fev. 2018.

Declaração de Cartagena. 22 nov. 1984. Disponível em: <http://www.acnur.org/fileadmin/scripts/doc.php?file=fileadmin/Documentos/portugues/BD_ Legal/Instrumentos_Internacionais/Declaracao_de_Cartagena>. Acesso em: 22 fev. 2018.

Global Trends - Forced Displacement in 2016. 19 jun. 2017a. Disponível em: <http://www.unhcr.org/5943e8a34.pdf>. Acesso em: 07 mar. 2018.

Refugee and Migrant Children in Europe Accompanied, Unaccompanied and Separated. Mid year Overview of Trends. jan-jun 2017. Out. 2017b. Disponível em: <https://data2.unhcr.org/en/documents/download/60348>. Acesso em: 12 abr. 2018.

ARAÚJO, Luiz Ernani Bonesso de. BARICHELLO, Stefania Eugenia. Aspectos históricos da evolução e do reconhecimento internacional do status de refugiado. Revista do Direito da UNISC, Santa Cruz do Sul, v.2, n. 46, p. 104-134, maio - ago. 2015. Disponível em: <https://online.unisc.br/seer/index.php/direito/article/view/4507/4076>. Acesso em: 16 mar. 2018 .

ARENDT, Hannah. Origens do Totalitarismo: Anti-semitismo, imperialismo, totalitarismo. Trad. Roberto Raposo. São Paulo: Companhia das Letras, 1989.

AZAMBUJA, Maria Regina Fay de. Violência sexual intrafamiliar: é possível proteger a criança? Revista Virtual Textos \& Contextos, $\mathrm{n}^{\circ}$ 5, nov. 2006. Disponível em: <http://revistaseletronicas.pucrs.br/ojs/index.php/fass/article/viewFile/1022/802>. Acesso em: 30 jan. 2018.

BAUMAN, Zigmunt. Estranhos à nossa porta. Rio de Janeiro: Zahar, 2017. 
BELOFF, Mary. Los derechos del niño em el sistema interamericano. Buenos Aires: Del Porto, 2004.

BOED, Roman. The State of the Right of Asylum in International Law. Duke Journal of Comparative \& International Law. vol. 5:1, p. 1-34, 1994. Disponível em: $<$ https://scholarship.law.duke.edu/cgi/viewcontent.cgi?article $=1342 \&$ context=djcil $>$. Acesso em: 07 mar. 2018.

BRASIL. Constituição da República Federativa do Brasil (1988). Brasília, DF, 05 out. 1988. Disponível em: <http://www.planalto.gov.br/ccivil_03/Constituicao/Constituicao.htm>. Acesso em: 30 jan. 2018.

Lei n. 8.069, de 13 de julho de 1990. Dispõe sobre o Estatuto da Criança e do Adolescente e dá outras providências. Diário Oficial da República Federativa do Brasil, Brasília, DF, 16 jul. $1990 . \quad$ Disponível em: <http://www.planalto.gov.br/ccivil_03/leis/L8069Compilado.htm>. Acesso em: 30 jan. 2018.

Lei Federal $n^{o} 9.474$ de 22 de julho de 1997. Define mecanismos para a implementação do Estatuto dos Refugiados de 1951, e determina outras providências. Brasília, DF, 22 jul. $1997 . \quad$ Disponível em: <http://www.planalto.gov.br/ccivil_03/leis/L9474.htm>. Acesso em: 30 jan. 2018.

. Lei Federal $n^{o} 13.445$ de 24 de maio de 2017. Define mecanismos para a implementação do Estatuto dos Refugiados de 1951, e determina outras providências. Brasília, DF, 22 jul. 1997. Disponível em: <http://www.planalto.gov.br/ccivil_03/_ato20152018/2017/lei/L13445.htm>. Acesso em: 08 jun. 2018.

Lei Federal $n^{\circ} 13.684$ de 21 de junho de 2018. Dispõe sobre medidas de assistência emergencial para acolhimento a pessoas em situação de vulnerabilidade decorrente de fluxo migratório provocado por crise humanitária; e dá outras providências. Brasília, DF, 21 jun. 2018. Disponível em: <http://www.planalto.gov.br/ccivil_03/_ato20152018/2018/Lei/L13684.htm>. Acesso em: 05 set. 2018.

BRUÑOL, Miguel Cillero. O interesse superior da criança no marco da Convenção Internacional sobre os Direitos da Criança. In: MENDEZ, Emílio García; BELOFF, Mary (orgs.). Infância, Lei e Democracia na América Latina. v. 1. Blumenau: FURB, 2001.

CARVALHO FILHO, José dos Santos. Manual de Direito Administrativo. São Paulo: Atlas, 2015.

COMITÊ NACIONAL PARA REFUGIADOS (CONARE). Refúgio em números. Jun. 2017. Disponível em: <http://www.acnur.org/fileadmin/scripts/doc.php?file=fileadmin/Documentos/ portugues/Publicacoes/2017/refugio-em-numeros-2010-2016>. Acesso em: 25 abr. 2018.

Refúgio em números $-3^{a}$ edição. Abr. 2018. Disponível em: <http://www.acnur.org/portugues/wp-content/uploads/2018/04/refugio-em-numeros_1104. pdf>. Acesso em: 05 set. 2018.

COMMITTEE ON THE RIGHTS OF THE CHILD (CRC). General Comment $n^{\circ} 6$ (2005). 
Treatment of unaccompanied and separated children outside their country of origin. Thirtyninth session - 17 May/3 June 2005. 1 september 2005. Geneva: CRC, 2005. Disponível em: <http://direitoshumanos.gddc.pt/2_1/IIPAG2_1_2_6_2.htm>. Acesso em: 16 mar. 2018.

CONSELHO NACIONAL DOS DIREITOS DA CRIANÇA E DO ADOLESCENTE (CONANDA); COMITÊ NACIONAL PARA OS REFUGIADOS (CONARE); CONSELHO NACIONAL DE IMIGRAÇÃO (CNIg); DEFENSORIA PÚBLICA DA UNIÃO (DPU). Resolução Conjunta de 09 de agosto de 2017. Disponível em: $<$ http://www.direitosdacrianca.gov.br/resolucoes/resolucoes-conjuntas-do-conanda2/resolucao-conjunta-conanda-conare-cnig-dpu-de/view>. Acesso em: 25 abr. 2018.

FIRMEZA, George Torquato. Brasileiros no exterior. Brasília: Fundação Alexandre de Gusmão, 2007.

FONSECA, Antonio Cezar Lima da. Direito da Criança e do Adolescente. 2 ed. São Paulo: Altas, 2012.

HABERMAS, Jürgen. A inclusão do outro - estudos de teoria política. Trad. George Sperber e Paulo Astor Soethe. São Paulo: Edições Loyola, 2002.

ITÁLIA. Legge 7 aprile 2017, n. 47. Disposizioni in materia di misure di protezione dei minori stranieri non accompagnati. Gazzetta Ufficiale della Repubblica Italiana, n. 93, de 21 de abril de 2017.20 Disponível em: <http://www.gazzettaufficiale.it/eli/id/2017/04/21/17G00062/sg>. Acesso em: 12 abr. 2018.

INTERNATIONAL REFUGEE ORGANIZATION (IRO). Constitution of the International Refugee Organization. 15 dez. 1946. Disponível em: <https://www.loc.gov/law/help/ustreaties/bevans/m-ust000004-0284.pdf> . Acesso em: 15 mar. 2018.

LIBERATI, Wilson Donizeti. Processo Penal Juvenil: a garantia da legalidade na execução da medida socioeducativa. São Paulo: Malheiros Editores, 2006.

. Comentários ao Estatuto da Criança e do Adolescente. 10. ed. São Paulo: Malheiros Editores, 2008.

Adolescente e ato infracional: medida socioeducativa é pena? 2. ed. São Paulo: Malheiros Editores, 2012.

LIGA DAS NAÇÕES. Convenção Relativa ao Estatuto Internacional dos Refugiados. Genebra, 28 de outubro de 1933. Disponível em: https://www.wdl.org/pt/item/11580/. Acesso em 15 mar. 2018.

LIMA, João Brígido Bezerra. et. al. Refúgio no Brasil: caracterização dos perfis sociodemográficos dos refugiados (1998-2014). Brasília: IPEA, 2017. Disponível em:

<http://www.ipea.gov.br/portal/images/stories/PDFs/livros/livros/170829_Refugio_no_Brasil. pdf>. Acesso em: 26 abr. 2018.

ORGANIZAÇÃO DOS ESTADOS AMERICANOS. (OEA). Convenção Americana sobre Direitos Humanos. 22 nov. 1969. Disponível em: 
<https://www.cidh.oas.org/basicos/portugues/c.convencao_americana.htm>. Acesso em: 09 mar. 2018.

ORGANIZAÇÃO DAS NAÇÕES UNIDAS. (ONU). Declaração Universal dos Direitos Humanos. 10 dez. $1948 . \quad$ Disponível <http://www.un.org/ga/search/view_doc.asp?symbol=A/RES/217(III)\&Lang=E>. Acesso em: 16 mar. 2018.

Convenção sobre os Direitos da Criança. 20 nov. 1989. Disponível em: <https://www.unicef.org/brazil/pt/resources_10127.htm>. Acesso em: 20 fev. 2018.

PEREIRA, Tânia da Silva. O melhor interesse da criança: um debate interdisciplinar. Rio de Janeiro: Renovar, 1999.

SALESIANI PER IL SOCIALE. Federazione SCS/CNOS (Servizi Civili e Sociali - Centro Nazionale Opere Salesiane). Il tutore volontario per minori stranieri non accompagnati. Sfida ed opportunità per la Famiglia Salesiana. Disponível em: <https://www.salesianiperilsociale.it/wp-content/uploads/2017/07/Guida_tutore_volontario_ msna_salesiani_per_il_sociale_2017.pdf>. Acesso em: 12 abr. 2018.

SARAIVA, João Batista Costa. Adolescente em conflito com a lei: da indiferença à proteção integral: uma abordagem sobre a responsabilidade penal juvenil 4. ed. Porto Alegre: Livraria do Advogado, 2013.

SISTEMA DI PROTEZIONI PER RICHIEDENTI ASILO E REFUGIATI (SPRAR). Rapporto sulla protezione Internazionale in Italia 2017. Out. 2017a. Disponível em: <http://www.sprar.it/wp-content/uploads/2017/11/2-Sintesi-Rapporto-Protezione-2017.pdf>. Acesso em: 18 abr. 2018.

Rapporto Annuale SPRAR. Atlante SPRAR 2016. 27 jun. 2017b. Disponível em: <http://www.sprar.it/wp-content/uploads/2017/06/Atlante-Sprar-2016-2017-RAPPORTOleggero.pdf $>$. Acesso em: 18 abr. 2018.

TAVARES, José de Farias. Direito da Infância e da Juventude. Belo Horizonte: Del Rey, 2001.

TEJADAS, Sílvia da Silva. Juventude e Ato Infracional: as múltiplas determinações da reincidência. Porto Alegre: EDIPUCRS, 2008.

WOMEN'S COMMISSION FOR REFUGEE CHILDREN AND WOMEN (WCRCW). Prison Guard or Parent? INS Treatment of Unaccompanied Refugee Children. Maio, 2002. New York: WCRCW, 2002. Disponível em: <https://www.womensrefugeecommission.org/images/zdocs/ins_det.pdf $>$. Acesso em: 26 abr. 2018.

\section{O Princípio do Melhor Interesse e a nova Condição Jurídica de Crianças Refugiadas Separadas ou Desacompanhadas: uma abordagem sobre Brasil e Itália}




\title{
Resumo
}

$\mathrm{O}$ artigo pretende abordar o tratamento conferido por Brasil e Itália às crianças refugiadas separadas ou desacompanhadas, por meio de seus respectivos documentos normativos. Nesse contexto, o presente trabalho apresenta, preliminarmente, o reconhecimento do sentimento de infância e a consolidação do princípio do melhor interesse da criança pela Convenção das Nações Unidas sobre Direitos da Criança de 1989. Além disso, trata da regulamentação do instituto do refúgio e sua aplicação aos menores de 18 (dezoito) anos. Posteriormente, busca demonstrar as inovações estabelecidas pela lei italiana $n^{\circ} 47 / 2017$ (Lei Zampa) e pela Resolução Conjunta de 09 de agosto de 2017 no Brasil, especificando os principais pontos regulamentados. Por fim, conclui-se que, apesar de haver, no ordenamento jurídico brasileiro, leis que abordem a temática do refúgio, há a necessidade de implementação de uma legislação específica que reconheça expressamente os direitos de crianças nessas condições, nos moldes do caso italiano. Para a elaboração deste estudo fora empregado o método de revisão bibliográfica, a partir da utilização de obras e artigos concernentes à literatura especializada nas áreas do Direito e da Ciência Política, bem como o método de análise de documentos oriundos de diversos órgãos nacionais e internacionais que versam sobre a temática exposta.

Palavras-Chave: Refugiados - crianças separadas ou desacompanhadas - Brasil - Itália.

\section{The Principle of Best Interest and the new Legal Condition of Separated or Unaccompanied Refugee Children: an approach on Brazil and Italy}

\begin{abstract}
The article intends to approach the treatment conferred by Brazil and Italy on separated or unaccompanied refugee children, through their respective normative documents. In this context, this paper presents, first of all, the recognition of the feeling of childhood and the consolidation of the principle of the best interest of the child by the 1989 United Nations Convention on the Rights of the Child. In addition, it deals with the regulation of the refugee institute and application to young people under 18 (eighteen) years. Subsequently, it seeks to demonstrate the innovations established by Italian Law No. 47/2017 (Zampa Law) and by the Joint Resolution of August 9, 2017 in Brazil, specifying the main regulated points. Finally, it is concluded that, although there are laws in Brazil that deal with refugee issues, there is a need to implement specific legislation that explicitly recognizes the rights of children under these conditions, in the manner of the Italian case. For the preparation of this study, the method of bibliographical revision was used, based on the use of works and articles related to the specialized literature in the areas of Law and Political Science, as well as the method of analysis of documents originating from various national and international bodies that on the subject matter.
\end{abstract}

Keywords: Refugees - separated and unaccompanied children - Brazil - Italy.

\section{El Principio del Mejor Interés y la Nueva Condición Jurídica de Niños Refugiados Separados o Sin Acompañante: un enfoque sobre Brasil e Italia}

\section{Resumen}

El artículo pretende abordar el trato verificado por Brasil e Italia a los niños refugiados separados o sin acompañante, por médio de sus documentos normativos respectivos. En este contexto, el trabajo presenta, de manera preliminar, el reconocimiento del sentimento de la infancia y la consolidación del principio del mejor interés del niño por la Convención de las Naciones Unidas sobre los derechos de los niños 1989. Además, trata de la regulación del instituto del refugio y su aplicación a los menores de 18 (dieciocho) años. Después, búsqueda demonstrar las innovaciones estabelecidas por la ley italiana nº47/2017 (Ley Zampa) y por la Resolución Conjunta de 09 de agosto de 2017 en Brasil, especificando los puntos pricipales regulados. Por fin, se concluye que, aunque hay, en el ordenamento jurídico brasileño, leyes que se acercan de la temática del refugio, hay la necesidad de la puesta en prática uma legislación específica que reconoce los derechos de los niños expresamente en esas condiciones, en los moldes del caso italiano. Para la elaboración deste estudio el método de la revisión de bibliographical había sido usado, empezando del uso de obras y artículos de la literatura especializada em las áreas del Derecho y de la Ciencias Políticas, así como el método del análisis de documentos procedentes de algunos organismos nacionales e internacionales que atcan la temática expuesta.

Palabras Clave: Refugiados - niños separados o sin acompañante - Brasil - Italia. 